\title{
AIP
}

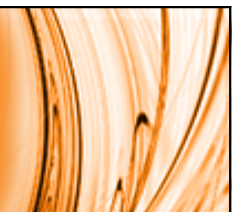

\section{Non-destructive thermal wave method applied to study thermal properties of fast setting time endodontic cement}

A. M. Picolloto, V. V. G. Mariucci, W. Szpak, A. N. Medina, M. L. Baesso, N. G. C. Astrath, F. B. G. Astrath, A. D. Santos, J. C. S. Moraes, and A. C. Bento

Citation: Journal of Applied Physics 114, 194701 (2013); doi: 10.1063/1.4829921

View online: http://dx.doi.org/10.1063/1.4829921

View Table of Contents: http://scitation.aip.org/content/aip/journal/jap/114/19?ver=pdfcov

Published by the AIP Publishing

\section{Articles you may be interested in}

Open photoacoustic cell for thermal diffusivity measurements of a fast hardening cement used in dental restoring J. Appl. Phys. 111, 014701 (2012); 10.1063/1.3673873

Thermal parameters of carbon nanotubes and potassium bromide composites

J. Appl. Phys. 109, 074902 (2011); 10.1063/1.3556737

Theoretical analysis of coupled diffuse-photon-density and thermal-wave field depth profiles photothermally generated in layered turbid dental structures

J. Appl. Phys. 105, 102022 (2009); 10.1063/1.3116128

Two-detector measurement system of pulse photothermal radiometry for the investigation of the thermal properties of thin films

J. Appl. Phys. 102, 064903 (2007); 10.1063/1.2778642

Thermal-wave nondestructive evaluation of cylindrical composite structures using frequency-domain photothermal radiometry

J. Appl. Phys. 97, 014911 (2005); 10.1063/1.1819999

\section{AIP $\mid$ chaos CALL FOR APPLICANTS Seeking new Editor-in-Chief}




\title{
Non-destructive thermal wave method applied to study thermal properties of fast setting time endodontic cement
}

\author{
A. M. Picolloto, ${ }^{1}$ V. V. G. Mariucci, ${ }^{1}$ W. Szpak, ${ }^{1}$ A. N. Medina, ${ }^{1}$ M. L. Baesso, ${ }^{1}$ \\ N. G. C. Astrath, ${ }^{1}$ F. B. G. Astrath, ${ }^{1}$ A. D. Santos,${ }^{2}$ J. C. S. Moraes, ${ }^{2}$ and A. C. Bento ${ }^{1, a)}$ \\ ${ }^{1}$ Departamento de Física, Grupo de Espectroscopia Fotoacústica e Fototérmica, Universidade Estadual \\ de Maringá - UEM, Av. Colombo 5790, 87020-900 Maringá, Paraná, Brazil \\ ${ }^{2}$ Departamento de Física e Química, Universidade Estadual Paulista "Júlio de Mesquita Filho" - UNESP, \\ Av. Brasil 56, 15385-000 Ilha Solteira, SP, Brazil
}

(Received 27 July 2013; accepted 26 October 2013; published online 15 November 2013)

\begin{abstract}
The thermal wave method is applied for thermal properties measurement in fast endodontic cement (CER). This new formula is developed upon using Portland cement in gel and it was successfully tested in mice with good biocompatibility and stimulated mineralization. Recently, thermal expansion and setting time were measured, conferring to this material twice faster hardening than the well known Angelus Mineral trioxide aggregate (MTA) the feature of fast hardening $(\sim 7 \mathrm{~min})$ and with similar thermal expansion $\left(\sim 12 \mu\right.$ strain $\left./{ }^{\circ} \mathrm{C}\right)$. Therefore, it is important the knowledge of thermal properties like thermal diffusivity, conductivity, effusivity in order to match thermally the tissue environment upon its application in filling cavities of teeth. Photothermal radiometry technique based on Xe illumination was applied in CER disks $600 \mu \mathrm{m}$ thick for heating, with prepared in four particle sizes $(25,38,45$, and 53) $\underline{\mu \mathrm{m}}$, which were added microemulsion gel with variation volumes $(140,150,160$, and 170) $\mu \mathrm{l}$. The behavior of the thermal diffusivity CER disks shows linear decay for increase emulsion volume, and in contrast, thermal diffusivity increases with particles sizes. Aiming to compare to MTA, thermal properties of CER were averaged to get the figure of merit for thermal diffusivity as $(44.2 \pm 3.6) \times 10^{-3} \mathrm{~cm}^{2} / \mathrm{s}$, for thermal conductivity $(228$ $\pm 32) \mathrm{mW} / \mathrm{cm} \mathrm{K}$, the thermal effusivity $(1.09 \pm 0.06) \mathrm{W} \mathrm{s} / \mathrm{cm}^{2} \mathrm{~K}$ and volume heat capacity $(5.2$ $\pm 0.7) \mathrm{J} / \mathrm{cm}^{3} \mathrm{~K}$, which are in excellent agreement with results of a disk prepared from commercial MTA-Angelus (grain size $<10 \mu \mathrm{m}$ using $57 \mu \mathrm{l}$ of distilled water). (C) 2013 AIP Publishing LLC. [http://dx.doi.org/10.1063/1.4829921]
\end{abstract}

\section{INTRODUCTION}

In the recent decades, science of life has experienced an enlargement of its exploiting field and, consequently, the renewing of many concepts on life and healthcare. Nowadays, so many powerful instruments and techniques are developed for observation and analysis of matter, producing new discoveries that could be useful for improving the human life. Aside to technologic achievement, there exists a great network between areas of science, promoting interfaces and cooperation in order to improve life quality in this modern world. Mainly in the healthcare, wider sense science and technological fields, there are many interests and demands for new materials claiming biocompatibility and therapeutics application hoping to solve simple question like human spare parts and restoring appliance that causes no rejection from the body or long-term recovering upon invasive surgeries. One field under fast development is the odontology, where many materials are developed aiming compatibility with human tissue and its environment in the mousse cavity. Tissues and tooth present particular physical properties that should be taken into account when biomaterial are to be used as filling roots, restoring teeth or aesthetical surgeries that need application of strange body. After a long time using

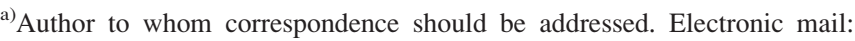
acbento@uem.br
}

mainly metal and its alloys, nowadays is quite common the use of new materials like hydroxyapatites and cement that activates tissue regenerating and others more stable that ultimate good matching for physical properties (like mechanical and thermal) between them and tissue environment.

Over two decades have passed after Refs. 1 and 2 reported his work on Mineral trioxide aggregate (MTA) claiming good properties for dental application, which has shown so far excellent physical, chemical, and biological properties. $^{3-5}$ MTA composition is based on fine hydrophilic particles of tricalcium silicate, tricalcium oxide, and tricalcium aluminate and silicate oxide as reported by Lee. ${ }^{1}$ Its similarity with commercial Portland cement (PC) has being subject of many authors ${ }^{6-8}$ what led some researchers to pursue alternatives based on PC that could improve some of tribological functions of the MTA formula. ${ }^{9}$ Originally sold at market as ProRoot-MTA, the manipulation of PC by a Brazilian company reached a new composite having $80 \%$ Portland cement and $20 \%$ bismuth oxide, this new material is available as MTA-Angelus (Angelus Soluções Odontologicas, Londrina, Brazil). ${ }^{10}$

The ProRoot-MTA as well as its modified formula MTA-Angelus has being criticized by clinicians mainly because of its poor handling characteristic and lengthy setting time. To overcome such drawback, it has being pointed out the new possible application of $\mathrm{MTA}^{4,11}$ as root filling material. Recently, it was proposed ${ }^{12,13}$ a new endodontic 
cement (named CER hereafter) composition with PC basis, a gel composed of water, barium sulfate, and an emulsifier with the function of improving the handling properties. This material was developed as sealer and has to promote antimicrobial action and mineralized tissue barrier formation upon calcium ion releasing in adjacent tissue. Although the results of indicate that CER may have some advantages over MTA, further studies is pointed out as needed to more suitably evaluate the bioactivity, thermal matching behavior to teeth when used as filling material, for instance. The interest for some biological and thermal properties of various dental cements has been investigated for some years in Brazil. ${ }^{14,15}$

Among the properties that the root-end filling cements should have, some of great importance, is the setting time for clinical intervention and thermal expansion coefficient compatible to teeth. Nevertheless, efforts have been made in the knowledge of other important properties desired for a root filling material aside setting time and thermal expansion one may find that thermal diffusivity, conductivity, and effusivity may bring contributing for complete characterization of such new material. In this sense, the proposal of this work is present a set of thermal parameters obtained by means of modern photothermal techniques such as photothermal radiometry (PTR) based on thermal wave method. The thermal properties were investigated in a nondestructive fashion and results correlated to both preparing condition particle size of the composite and emulsion volume used in setting the cement.

\section{PTR THEORY AND COUPLING LAYER CONTRIBUTION}

\section{A. 1-D thermal wave model}

In this model, the emitted radiation is proportional to the ultimate modulated surface temperature $\theta_{\mathrm{AC}}$ of a slab being heated by a light source considering heat source in the bulk and its thermal wave coupling from the interface contact between the slab and its backing. The simplest way of understanding the geometry for this heat transfer problem is to accept the system as a coating on a substrate or a layer film onto another layer being one of them illuminated by a modulated white light or laser. This radiation depends on both sample geometry, infrared collection angle and also on the area of the detector. Based upon Stefan-Boltzmann emission law, one can show that the PTR signal can be written as ${ }^{16}$

$$
S_{P T R}=\Psi\left(\phi, \lambda_{d}, T, D\right) \frac{\partial W\left(\lambda_{d}\right)}{\partial \theta} \Delta \lambda \theta_{A C}
$$

being $\Psi\left(\phi, \lambda_{d}, T, D\right)=\varepsilon A \sin ^{2}(\phi) T\left(\lambda_{d}\right) D\left(\lambda_{d}\right)$ the transfer function of the detection where $\varepsilon$ is the surface emissivity, A is the detector area, $\phi$ is the collecting angle, D is the detector spectral sensitivity for the spectral range $\Delta \lambda$ centered at the detection wavelength $\lambda_{\mathrm{d}}, \mathrm{T}$ is the transmission efficiency of the infrared optics, $W\left(\lambda_{d}, \theta\right)=\left\{C_{1} \lambda^{-5} /\left[\exp \left(C_{2} / \lambda \theta\right)-1\right]\right\}$ is the Planck's radiation intensity formula with $\mathrm{C}_{1}=2 \mathrm{hc}^{2}$ and $\mathrm{C}_{2}=\mathrm{hc} / \mathrm{k}_{\mathrm{B}}$ being the radiation constants and $\theta$ is the absolute temperature in Kelvin. The sample's modulated surface temperature is $\theta_{\mathrm{AC}}$ and it is the solution for a differential heat diffusion equation. In the thermal wave scheme, the $\theta_{\mathrm{AC}}$ was derived by Bennett and Patty theory ${ }^{17}$ using photoacoustic method with detection by means of microphone but nowadays a remote fashion of detection of the thermal waves is based on PTR. The technique PTR measure the emission of heat from a heated surface using the superposition scheme of thermal waves arising from a bulk coating. ${ }^{18-21}$ For the PTR scheme, the signal and its phase variation are due thermal wave produced in the bulk of a coating with depletion or accumulation in the interfaces. For a coating (sample layer) of thickness $\mathrm{L}$ it follows that

$$
\begin{aligned}
\theta_{A C}= & \frac{I_{0} \beta}{2 K \sigma\left(1-R_{b} e^{-2 \sigma L}\right)} \\
& \times\left[\frac{1-e^{-(\beta+\sigma) L}}{\beta+\sigma}+\frac{R_{b} e^{-2 \sigma L}\left(1-e^{-(\beta-\sigma) L}\right)}{\beta-\sigma}\right],
\end{aligned}
$$

where $I_{0}$ is the incident power, $\beta$ is the optical absorption coefficient, $\mathrm{K}$ is the coating thermal conductivity, and $\sigma=(1+j) a_{s}$ (with $a_{s}=\sqrt{\omega / 2 \alpha}$ ) defines the complex thermal wave number and depends on modulation frequency $\omega=2 \pi \mathrm{f}$ and thermal diffusivity, $\alpha$, the thermal wave interfacial coefficient is defined as dependent on the thermal effusivities ratio $\left(\mathrm{e}_{\mathrm{i}} / \mathrm{e}_{\mathrm{j}}\right)$ and given by $R_{b}=\left[1-\left(e_{S} / e_{C}\right)\right]$ $/\left[1+\left(e_{S} / e_{C}\right)\right]$ where $e_{i}=K_{i} / \sqrt{\alpha_{i}}$, being $\mathrm{i}=$ 's' for the substrate and $\mathrm{i}=$ ' $\mathrm{c}$ ' for the cement, respectively.

In most case, one can simplify Eq. (2) for the thermally thick $(|\sigma \mathrm{L}| \gg 1)$ and opaque $(|\beta \mathrm{L}| \gg 1)$ condition, thus choosing a wavelength such that the situation $\beta \gg|\sigma|$ is allowed, Eq. (2) is rewritten to give

$$
\theta_{A C} \cong \frac{I_{0}\left(1+R_{b} e^{-2 \sigma L}\right)}{2 K \sigma\left(1-R_{b} e^{-2 \sigma L}\right)} .
$$

By fitting Eq. (2) or Eq. (3) onto the signal or phase data, one can calculate the thermophysical properties of the coating.

\section{B. 1-D thermal wave model with interface layer correction}

A wider discussion on the problem inferring about boundaries for thermal waves propagating in layered system with contact resistance is referenced to readers in Mandelis book, $^{22}$ whose treatment deal with many problems in the photothermal field aiming to introduce a unification of mathematical framework for the so-called diffusion-wave field using Green functions formalism. In most cases, the coupling layer between substrate and coating are not perfect and thermal contact resistance may come out. This cumbersome problem can be faced upon supposing that this coupling layer is thin enough to be neglected, but for a nonperfect contact it could be seen as a new layer. Moreover, such new layer could present thermal wave interfacial accumulation or depletion, which one may assume to be responsible for an effective thermal wave coupling coefficient, considering the Bennet-Patty model for thermal wave method. In the case of new layer, one has to write the functional of temperature for an opaque coating adhered to a substrate semi-infinite as follows: ${ }^{16,22}$ 


$$
\theta_{A C} \cong \frac{I_{0}}{2 K_{c} \sigma_{c}}\left[\frac{1+\Gamma \exp \left(-2 \sigma_{c} L_{c}\right)}{1-\Gamma \exp \left(-2 \sigma_{c} L_{c}\right)}\right]
$$

Here, the effective thermal wave coupling coefficient $\Gamma$ becomes complex and must carry on all information about the coating layers and their thermal properties and it can be written as

$$
\Gamma=\frac{R_{g c}+R_{s g} \exp \left(-2 \sigma_{g} L_{g}\right)}{1+R_{g c} R_{s g} \exp \left(-2 \sigma_{g} L_{g}\right)}
$$

The subscript $g$ indicates the thermal grease. In this equation, the relation between interfacial coefficient for the two interfaces, coating-coupling layer $(\mathrm{c}-\mathrm{g})$ and coupling layer-substrate $(\mathrm{g}-\mathrm{s})$ can be readily written as

$$
R_{g c}=\frac{1-b_{g c}}{1+b_{g c}} \quad \text { With } \quad b_{g c}=\frac{K_{g} \sigma_{g}}{K_{c} \sigma_{c}} .
$$

Being $b_{g c}$ the effusivity ratio for glue-coating interface and also being the effusivity ratio for substrate-glue interface,

$$
R_{s g}=\frac{1-b_{s g}}{1+b_{s g}} \quad \text { With } \quad b_{s g}=\frac{K_{s} \sigma_{g}}{K_{g} \sigma_{s}} .
$$

In many photothermal models, one may prefer the use of phases of signal instead of its magnitude, which is of course due to phases to be more sensitive in the frequency domain. Therefore, the simulation of phase shift for Eqs. (3) and (4) for cases II(A) and II(B) can be very advantageous to justify why choosing phases shift for fittings instead of the PTR signal amplitude. ${ }^{22}$ In Fig. 1, PTR phase shift is shown for a particular set of interfacial coefficient for the case of a perfect contact between coating and substrate, case II(A). The $\mathrm{x}$-axis is the thermal thickness (that uses $\alpha=0.06 \mathrm{~cm}^{2} / \mathrm{s}$ and $\mathrm{L}_{\mathrm{c}}=600 \mu \mathrm{m}$. Phases shift toward positive value for interfacial coefficient negative, peeking in the very early thermally thin region $(|\sigma \mathrm{L}| \ll 1)$, a notch is shown near $(|\sigma \mathrm{L}| \sim 1.5)$

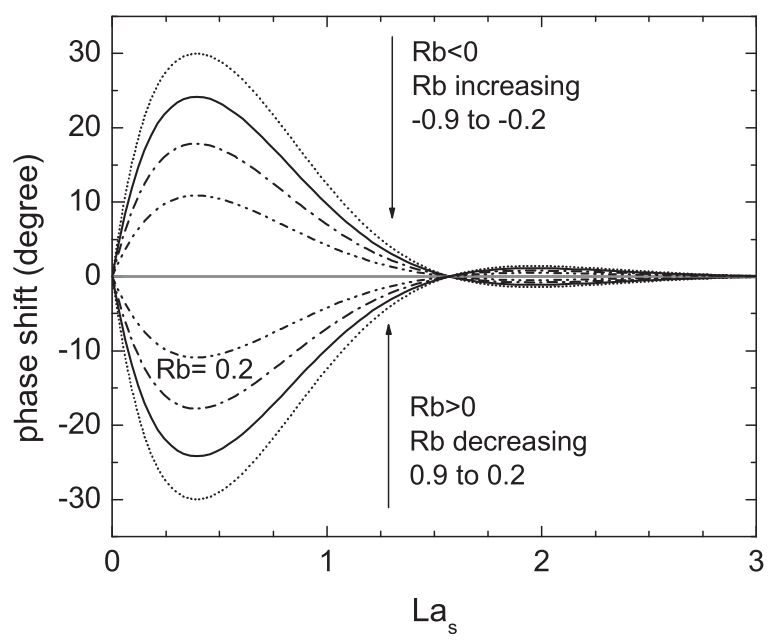

FIG. 1. PTR prediction for the optically opaque condition for phase shift of Eq. (3) as a function of thermal thickness. PTR is parameterized against thermal wave interfacial coefficient $R_{b}$. The value $R_{g}$ was considered for simulation equal to 1 . what justify using phases since the signal amplitude is extremely attenuated for $|\sigma \mathrm{L}|>1.0$. On the other hand, in Figs. 2(a) and 2(b) it is simulated the influence of the coupling layer on both amplitude and phase, considering one case of Fig. 1 with no coupling layer and interfacial coefficient being $\mathrm{R}_{\mathrm{sg}}=+0.3, \alpha=0.06 \mathrm{~cm}^{2} / \mathrm{s}$, and $\mathrm{L}_{\mathrm{c}}=600 \mu \mathrm{m}$ corresponding to the first curve in Fig. 1 below the $\mathrm{x}$-axis. This curve is naturally modified when the coupling layer is considered with interfacial coefficient $R_{\mathrm{gc}}$ goes from -1 to +1 . Clearly one can observe an inversion of the phase starting near $45^{\circ}$ and going toward $-45^{\circ}$, and the same pattern is seen for normalized amplitude that goes from 0 to $+\infty$ for $\mathrm{R}_{\mathrm{gc}}$ given from -1 to +1 . Comparing both figures one can see that the coupling layer is changing the phase shift in the opposite direction compared to PTR with no coupling layer, case II(A). Phase shift goes to $-45^{\circ}$ as the coupling factor $\mathrm{R}_{\mathrm{gc}}$ goes from 0 to +1.0 and in opposite it goes to $+45^{\circ}$ when $R_{\mathrm{gc}}$ increases from 0 to -1.0 . When simulated for $\mathrm{R}_{\mathrm{sg}}=-0.3$ the behavior of the phase difference (Fig. 2) is shown the same for the case $R_{\mathrm{sg}}>0$.

\section{MATERIAL AND METHODS}

\section{A. Sample preparation}

Samples used in the PTR adherence experiment were disks of fast endodontic cement (CER), which were prepared in the Physics Department of Ilha Solteira University, Brazil. Portland cement, gel composed of water, barium sulfate $\left(\mathrm{BaSO}_{4}\right)$, and an emulsifier were mixed with stainless spatula on a thick glass plate to perform the CER composite. Before it was dried, the CER mixture was placed in a stainless steel plate with circular holes of $5 \mathrm{~mm}$ in diameter and $1 \mathrm{~mm}$ thick supported on a glass tablet, filling the holes. Another glass plate was rested on top gentle to assure the uniformity of thicknesses. Although the batches were managed at room temperature, the final system comprised of "mass tablet/stainless steel holder/glass top" was left to rest in an oven with temperature controlled at $37^{\circ} \mathrm{C}$ and humidity kept between $95 \%$ and $100 \%$. $^{12,13}$

The samples were prepared in batches of sixteen disks using four sieves with $25,38,45$, and $53 \mu \mathrm{m}$, varying for

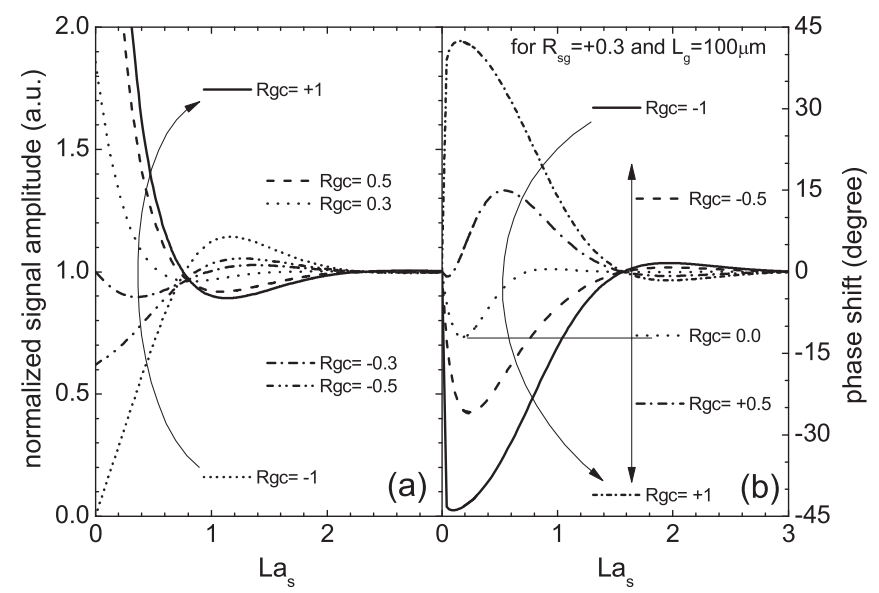

FIG. 2. PTR prediction for adherence layer considering amplitude (a) and phase shift (b) of Eq. (4) as a function of thermal thickness. PTR amplitude and signal phase is parameterized against thermal wave interfacial coefficient Rgc (thermal paste-coating interface). 
each particle size the relation powder/liquid, being one of each for PTR measurements. For example, an amount of $600 \mathrm{mg}$ of clinker powder produces one set of four CER disks with grain size $25 \mu \mathrm{m}$ that was mixed with emulsion volumes of $140,150,160$, and $170 \mu \mathrm{l}$, respectively. Following this procedure, other CER disks were prepared with particle sizes 38,45 , and $53 \mu \mathrm{m}$, performing a sixteen set of samples. The average thickness after cured was Lc $600 \mu \mathrm{m}$. MTA powder grade less than $10 \mu \mathrm{m}$ was bought at local market and it was prepared as early described, but with $57 \mu \mathrm{l}$ as recommended by manufacture's recipes. The curing time of samples of CERs was inspected by means of a Gilmore needle each 2 min until no more penetration was guaranteed. These results led to thermal expansion data and setting time of CER but will not be the subject of this work. $^{13,23}$

\section{B. Thermal wave method: PTR experimental setup}

The PTR setup is comprised by a radiation source, modulation system and infrared sensor, which drives the signal into a Lock-in amplifier that reads the signal as a function of modulation frequency at an $\mathrm{x}$ point at the surface on sample. A personal computer is able to move the step-motor $\mathrm{x}$ stage, controlling data transfer and storing them for further analysis. The setup is shown in Fig. 3(a), which differently of the usual PTR setups, a $1000 \mathrm{~W}$-Xe arc white lamp source (Oriel corporation model 68820) emitting from UV up to $4 \mu \mathrm{m}$ is used instead a laser. Lamp was settled to $750 \mathrm{~W}$ and a chopper (Stanford Research model SR540) modulated the light. The thermopile infrared sensor (Oriel model 71765) with Ge window was used to read the thermal radiation in the range of 8-14 $\mu \mathrm{m}$ and this signal was feed into the Lockin (EG\&G, model 5110). Amplitude and phases of the signals were collected and stored for fittings purposes using Eqs. (3) and (4). Figure 3(b) shows the geometry for the sample when fixed onto of the stainless steel substrate. The coupling paste was manufactured by Simavi Co. and bought from local electronic store (Simavi Co. Brazil, silicon grease with zinc oxide). All samples of CER (based in commercial Cimento Portland Comum CP I e CP I-S, NBR 5732), MTA (MTAAngelus Brazil code 820) and a layer of thermal paste were supported in a single strip of stainless steel (SS, commercial blades from local market) $3164 \mu \mathrm{m}$ thick in order to run all of them at a time, for each frequency from 1 to $25 \mathrm{~Hz}$. The sketch of sample holder is shown in Fig. 3(c), CER were fixed side by side and a small gap was left to identify the phase shift from substrate when the light passes from one sample to another in the line of scan.

\section{RESULTS AND DISCUSSION}

\section{A. Thermal coupling analysis}

An important role of thermal grease is the ability to dissipate heat from the surface of the paste and the material in which it will be applied. For the chemical composition of the thermal grease is very important that its surface (which is very irregular) is composed of a plastic material, e.g., silicone oil and other component that is also a good conducting (zinc oxide, carbon black, graphite, and silver). ${ }^{24,25}$

To check the influence of thermal grease on the thermal wave response, under absorbing conditions for an optically opaque layer, grease were put on top of two different substrates (grade American Iron and Steel Institute-AISI), AISI 304 or AISI 316 stainless steel and glass soda lime. Grease thicknesses were $(38,90,166$, and 343) $\mu \mathrm{m}$ on glass and $(10,60,100,170$, and 340) $\mu \mathrm{m}$ on stainless steel. PTR scans were done using light on the grease surface for both
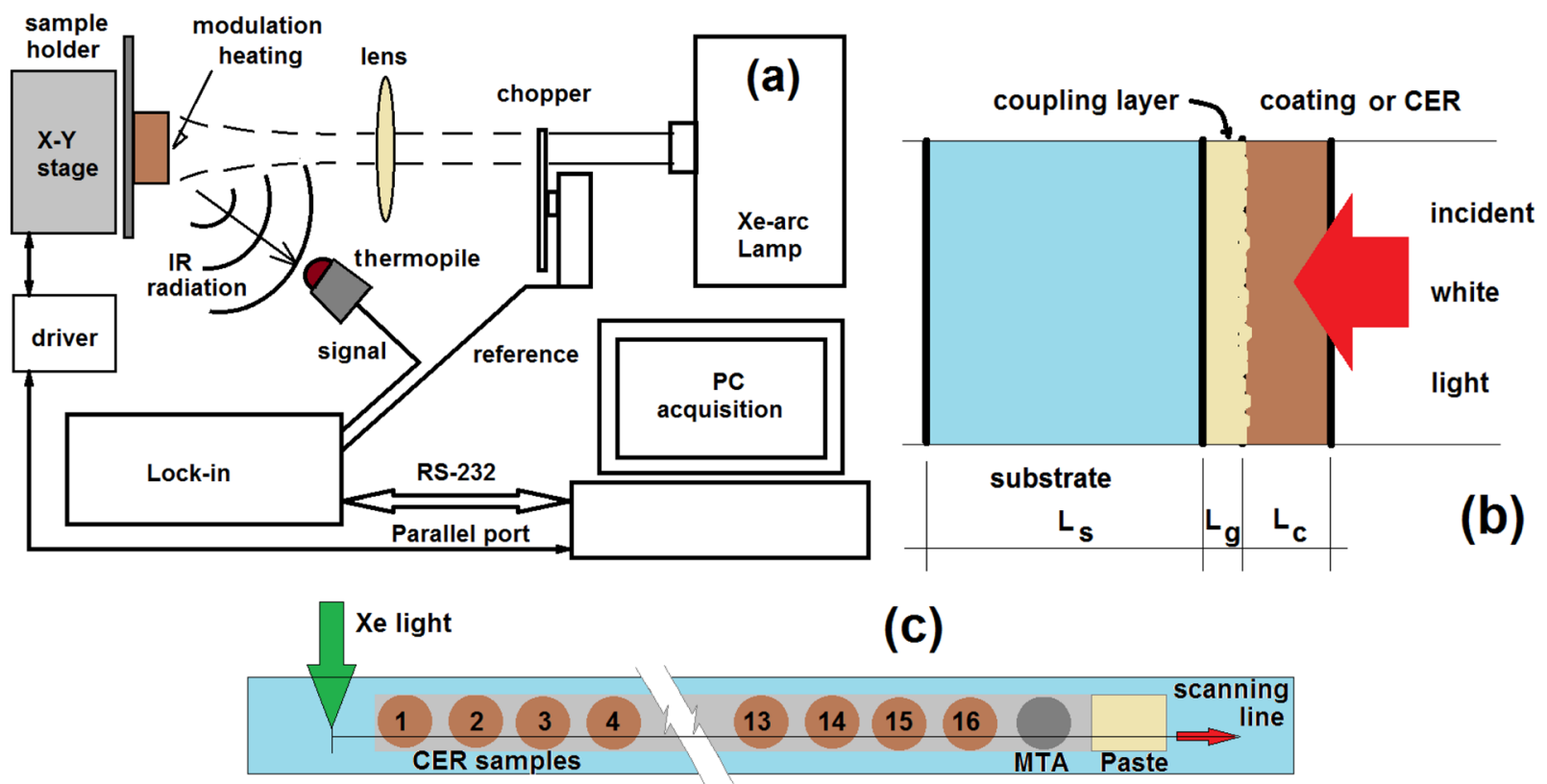

FIG. 3. (a) Thermal wave experimental setup using white lamp Xe arc. (b) Geometry used for sample coupling onto substrate, a thermal coupling was guaranteed by a thin layer of paste and it is considered as a layer in the PTR considering the condition optically opaque with influence adherence model. (c) Sample holder of stainless steel detailing the light scan and samples CER location with Ls $\sim 600 \mu \mathrm{m}$, fixing layer of paste was about Lg $\sim 220 \mu \mathrm{m}$ stainless strip Ls $\sim 3164 \mu \mathrm{m}$. 
substrates, by means of three different sources of radiation, the xenon arc lamp emitting polychromatic white light with a power $800 \mathrm{~W}$, the argon laser with $\lambda=514 \mathrm{~nm}$ (model Innova 90-Plus Coherent $\mathrm{TEM}_{00}-6 \mathrm{~W}$, multiline mode), with power applied to the experiment $675 \mathrm{~mW}$, and, finally, the laser diode/Transistor-transistor logic modulated (TTL) (model DHMO-M), $\lambda=532 \mathrm{~nm}$ and power $500 \mathrm{~mW}$. The spot onto samples was large enough to assure plane illumination $(\sim 4 \mathrm{~mm})$.

It was imperative to know the thermal grease stability under exposure to environment and time as its physicalchemical properties may be changed with some sort of influence in the PTR experiment, which justify using many light source and substrates for the grease layer. Since thermal properties such as the diffusivity and effusivity of this grease is needed to model the adherence layer as recalled in the model presented in Sec. II, PTR influence from the adherence layer is accounted in Eq. (3). The information about the thermal properties of substrates used in the measurements of the grease layer is tabulated elsewhere. ${ }^{26,27}$

The range of modulation frequency sweep was from 0.5 to $80 \mathrm{~Hz}$, with different limits in each experiment. Figures 4(a) and 4(b) show the plots of the phase shift versus $\mathrm{Lf}^{0.5}$ in fitting the grease layer for both substrates using the sources Ar-laser and Xe-arc lamp. Results show consistency independent on the radiation source used. From fitting data one can obtain $\alpha$ and R, which are represented by the straight line in Figs. 4(a) and 4(b). The average parameters from measurements and those calculated afterwards using $\alpha$ and $\mathrm{R}$ are $\alpha_{\text {grease }}=(7.6 \pm 0.4) \times 10^{-3}$ $\mathrm{cm}^{2} / \mathrm{s}$ and $\mathrm{R}_{\mathrm{b}}=+(0.25 \pm 0.03)$, which led to $e_{\text {grease }}$ $=(0.43 \pm 0.03) \mathrm{W} \mathrm{s}{ }^{0.5} / \mathrm{cm}^{2} \mathrm{~K}, \mathrm{~K}_{\text {grease }}=(38.0 \pm 4.0) \mathrm{mW} / \mathrm{cm}$ $\mathrm{K}$, and $\rho \mathrm{c}_{\mathrm{p} \text { grease }}=(4.9 \pm 0.4) \mathrm{J} / \mathrm{cm}^{3} \mathrm{~K}$. Maximum phase shift were $\sim 11^{\circ}$ when using white light, Fig. 4(a) and $\sim 13^{\circ}$ for Ar-ion laser at $514 \mathrm{~nm}$, Fig. 4(b).

\section{B. Cement analysis}

\section{CER results}

Although other photoacoustic methods could be used for measuring thermal diffusivities of the CER, remote PTR is chosen because it presents advantage compared to open photoacoustic cell method (OPC) in managing porous material. Troubles such as pressure leaking or thermal bending effects are securely disregarded when using the PTR and generally porous sample should be pretreated with hydrophobic layers on surfaces to assure the closeness of photoacoustic chamber. Furthermore, PTR's remote feature allows one to measure the infrared radiation from sample upon its illumination with a non-coherent light source, since enough heat can be generated at sample surface.

The trouble in dealing with thin slab instead of CERcoating brings to the PTR experiment a little difficult related to contact as this method supposes that a coating having good contact with a substrate is essential to the method. To overcome this need, and due the high porous character of the dental cement CER, aside its fragility as well, the setup of samples were made up fixing all samples on the stainless steel strip by means of a thin layer of thermal coupling grease, as shown in Fig. 3(c). The grease layer thickness was in average
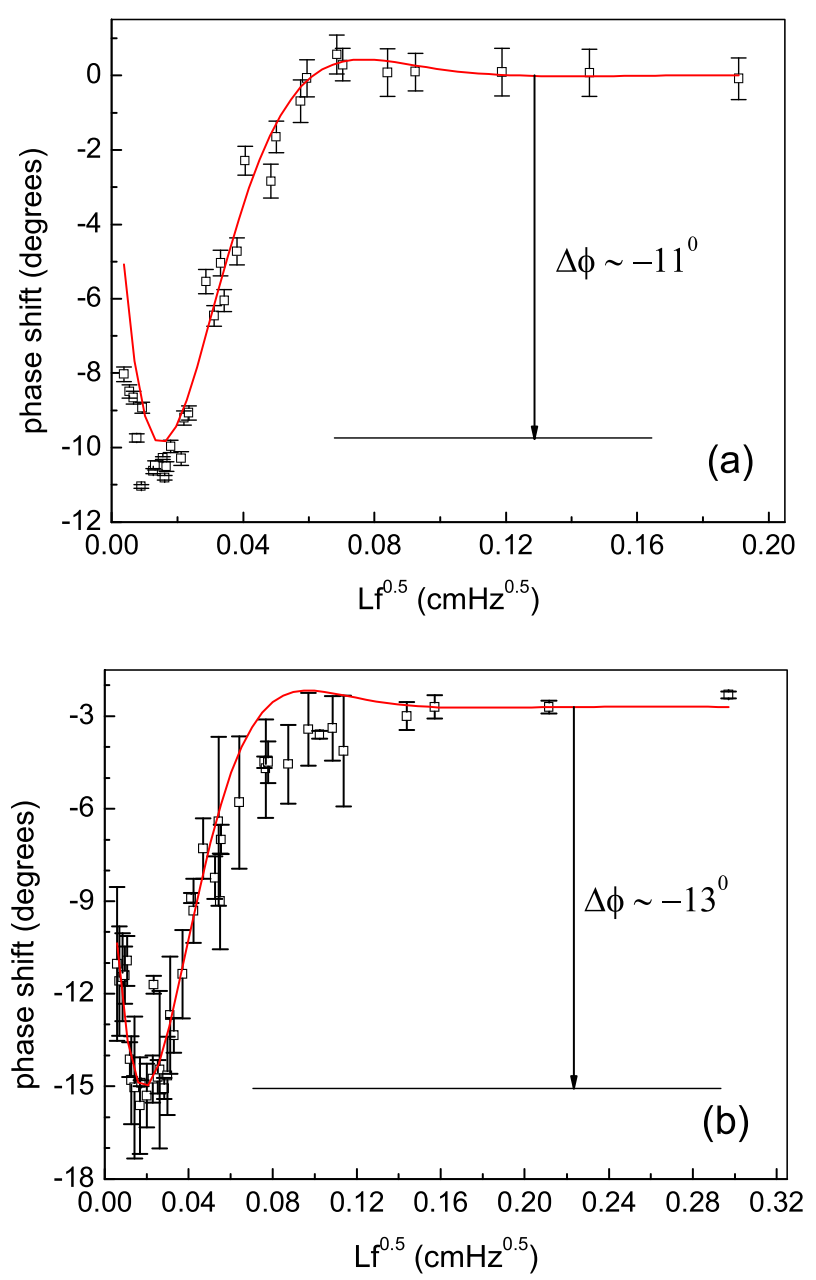

FIG. 4. Results for PTR fitting of thermal grease using Eq. (3). (a) Grease on stainless steel substrate and source Xe-arc lamp. (b) Grease on stainless steel substrate and source of illumination Ar-ion laser. Symbols are experimental data and lines are fittings.

about $37 \%$ of the CER thickness, being typically of the order of $218 \mu \mathrm{m}$ for grease and $595 \mu \mathrm{m}$ for CER, the whole batch of CER is given in Table I, which also shows fitting results for the whole thermal parameter. Table I also includes values for MTA, Portland and thermal grease obtained in this work.

Substrate was supported and moved by the X-Y stage in a scanning line that covers about $157 \mathrm{~mm}$ long including substrate, thermal grease, and MTA areas. Thus, white light passes each CER disk. As to exemplify a single scanning at $25 \mathrm{~Hz}$, Fig. 5 shows on top only a part of the strip shown in Fig. 3(c), which is swept by light. One can see clearly the phase shifts for samples from 1 to $4(140 \mu \mathrm{l}$ to $170 \mu \mathrm{l})$ of CER disks prepared with grain size of $25 \mu \mathrm{m}$. The main feature in this figure is that a quasi-flat plateau is developed for each CER as a response of heating and in between the phases shift down to match the phase of substrate. Data points are phase shift at a position on each sample and the "plateau" is the extension of them. The fluctuation of phase for each plateau is expected when heating a sample prepared from powdered particles (such as ceramic or cements). This is an effect of the surface porous varying in size and geometry, which can make the local amplitude of temperature or its phase to be different from a void compared to a solid part. These phases can reflect those variations in the form 
TABLE I. Thermal parameters measured and calculated with the influence of thermal grease.

\begin{tabular}{|c|c|c|c|c|c|c|c|c|c|c|c|c|}
\hline \multicolumn{3}{|c|}{ Samples and thicknesses } & \multicolumn{2}{|c|}{ Fitted from phase of Eq. (4) } & \multicolumn{3}{|c|}{ Calculated from phase } & \multicolumn{2}{|c|}{ Fitted from amplitude of Eq. (4) } & \multicolumn{3}{|c|}{ Calculated from amplitude } \\
\hline $\operatorname{CER}(\mu \mathrm{m} / \mu \mathrm{l})$ & $\mathrm{Lc}( \pm 1 \mu \mathrm{m})$ & $\operatorname{Lg}( \pm 1 \mu \mathrm{m})$ & $\alpha\left(10^{-3}\right)\left(\mathrm{cm}^{2} / \mathrm{s}\right)$ & $\mathrm{R}_{\mathrm{gc}}$ & $\mathrm{e}\left(\mathrm{Ws}^{0.5} / \mathrm{cm}^{2} \mathrm{~K}\right)$ & $\mathrm{K}(\mathrm{mW} / \mathrm{cm} \mathrm{K})$ & $\rho \mathrm{c}_{\mathrm{p}}\left(\mathrm{J} / \mathrm{cm}^{3} \mathrm{~K}\right)$ & $\alpha\left(10^{-3}\right)\left(\mathrm{cm}^{2} / \mathrm{s}\right)$ & $\mathrm{R}_{\mathrm{gc}}$ & $\mathrm{e}\left(\mathrm{Ws}^{0.5} / \mathrm{cm}^{2} \mathrm{~K}\right)$ & $\mathrm{K}(\mathrm{mW} / \mathrm{cm} \mathrm{K})$ & $\rho \mathrm{c}_{\mathrm{p}}\left(\mathrm{J} / \mathrm{cm}^{3} \mathrm{~K}\right)$ \\
\hline $25 / 140$ & 580 & 216 & $40.2 \pm 3.3$ & $0.40 \pm 0.02$ & $1.02 \pm 0.06$ & $205 \pm 28$ & $5.1 \pm 0.7$ & $41.5 \pm 2.4$ & $0.38 \pm 0.01$ & $0.99 \pm 0.04$ & $202 \pm 13$ & $4.9 \pm 0.6$ \\
\hline $25 / 150$ & 532 & 217 & $39.4 \pm 3.2$ & $0.45 \pm 0.03$ & $1.16 \pm 0.07$ & $230 \pm 32$ & $5.8 \pm 0.8$ & $40.4 \pm 2.3$ & $0.43 \pm 0.02$ & $1.12 \pm 0.05$ & $226 \pm 16$ & $5.6 \pm 0.7$ \\
\hline $25 / 160$ & 592 & 216 & $41.7 \pm 3.4$ & $0.40 \pm 0.02$ & $1.02 \pm 0.06$ & $209 \pm 29$ & $5.0 \pm 0.7$ & $42.6 \pm 2.5$ & $0.38 \pm 0.01$ & $1.00 \pm 0.04$ & $205 \pm 13$ & $4.8 \pm 0.6$ \\
\hline $25 / 170$ & 565 & 217 & $37.8 \pm 3.0$ & $0.43 \pm 0.03$ & $1.09 \pm 0.06$ & $212 \pm 29$ & $5.6 \pm 0.8$ & $36.4 \pm 2.1$ & $0.44 \pm 0.02$ & $1.17 \pm 0.05$ & $223 \pm 16$ & $6.1 \pm 0.9$ \\
\hline $38 / 140$ & 564 & 228 & $42.4 \pm 3.4$ & $0.41 \pm 0.02$ & $1.04 \pm 0.06$ & $214 \pm 30$ & $5.1 \pm 0.7$ & $44.8 \pm 2.6$ & $0.38 \pm 0.01$ & $0.99 \pm 0.04$ & $211 \pm 14$ & $4.7 \pm 0.6$ \\
\hline $38 / 150$ & 645 & 216 & $48.3 \pm 3.4$ & $0.35 \pm 0.02$ & $0.91 \pm 0.05$ & $200 \pm 28$ & $4.2 \pm 0.6$ & $48.5 \pm 2.8$ & $0.35 \pm 0.01$ & $0.93 \pm 0.03$ & $205 \pm 13$ & $4.2 \pm 0.5$ \\
\hline $38 / 160$ & 486 & 217 & $33.7 \pm 2.7$ & $0.51 \pm 0.03$ & $1.34 \pm 0.08$ & $246 \pm 34$ & $7.3 \pm 1.0$ & $30.7 \pm 1.8$ & $0.59 \pm 0.02$ & $1.08 \pm 0.08$ & $189 \pm 19$ & $6.1 \pm 0.9$ \\
\hline $38 / 170$ & 565 & 225 & $42.7 \pm 3.5$ & $0.41 \pm 0.02$ & $1.04 \pm 0.06$ & $214 \pm 30$ & $5.0 \pm 0.7$ & $44.2 \pm 2.6$ & $0.38 \pm 0.01$ & $1.01 \pm 0.04$ & $212 \pm 14$ & $4.8 \pm 0.6$ \\
\hline $45 / 140$ & 640 & 230 & $44.5 \pm 3.6$ & $0.36 \pm 0.02$ & $0.93 \pm 0.05$ & $196 \pm 27$ & $4.4 \pm 0.6$ & $47.3 \pm 2.7$ & $0.33 \pm 0.01$ & $0.90 \pm 0.03$ & $195 \pm 12$ & $4.1 \pm 0.5$ \\
\hline $45 / 150$ & 610 & 226 & $40.5 \pm 3.3$ & $0.39 \pm 0.02$ & $1.00 \pm 0.06$ & $201 \pm 28$ & $5.0 \pm 0.7$ & $40.8 \pm 2.4$ & $0.40 \pm 0.02$ & $1.04 \pm 0.04$ & $210 \pm 15$ & $5.1 \pm 0.7$ \\
\hline $45 / 160$ & 617 & 232 & $43.8 \pm 3.5$ & $0.35 \pm 0.02$ & $0.91 \pm 0.05$ & $191 \pm 26$ & $4.4 \pm 0.6$ & $44.4 \pm 2.6$ & $0.35 \pm 0.01$ & $0.93 \pm 0.03$ & $195 \pm 13$ & $4.4 \pm 0.5$ \\
\hline $45 / 170$ & 598 & 217 & $43.1 \pm 3.5$ & $0.42 \pm 0.02$ & $1.06 \pm 0.06$ & $221 \pm 31$ & $5.1 \pm 0.7$ & $43.0 \pm 2.5$ & $0.42 \pm 0.02$ & $1.11 \pm 0.04$ & $229 \pm 16$ & $5.3 \pm 0.7$ \\
\hline $53 / 140$ & 640 & 218 & $51.5 \pm 4.2$ & $0.37 \pm 0.02$ & $0.95 \pm 0.06$ & $215 \pm 30$ & $4.2 \pm 0.6$ & $51.2 \pm 3.0$ & $0.37 \pm 0.01$ & $0.98 \pm 0.04$ & $222 \pm 15$ & $4.3 \pm 0.5$ \\
\hline $53 / 150$ & 625 & 222 & $42.6 \pm 3.4$ & $0.40 \pm 0.02$ & $1.02 \pm 0.06$ & $210 \pm 29$ & $4.9 \pm 0.7$ & $41.9 \pm 2.4$ & $0.41 \pm 0.02$ & $1.08 \pm 0.04$ & $221 \pm 16$ & $5.3 \pm 0.7$ \\
\hline $53 / 160$ & 735 & 216 & $58.2 \pm 4.7$ & $0.31 \pm 0.02$ & $0.83 \pm 0.05$ & $201 \pm 28$ & $3.5 \pm 0.5$ & $60.2 \pm 3.5$ & $0.30 \pm 0.01$ & $0.83 \pm 0.03$ & $205 \pm 12$ & $3.4 \pm 0.4$ \\
\hline $53 / 170$ & 606 & 209 & $42.9 \pm 3.5$ & $0.41 \pm 0.02$ & $1.05 \pm 0.06$ & $217 \pm 30$ & $5.1 \pm 0.7$ & $45.1 \pm 2.6$ & $0.39 \pm 0.01$ & $1.02 \pm 0.04$ & $216 \pm 14$ & $4.8 \pm 0.6$ \\
\hline \multicolumn{13}{|c|}{ Reference material measured } \\
\hline $\begin{array}{l}\text { Thermal } \\
\text { Grease/Paste }^{(a)}\end{array}$ & 115 & - & $7.6 \pm 0.4$ & $-(0.25 \pm 0.03)$ & $0.43 \pm 0.03$ & $38 \pm 4$ & $4.9 \pm 0.4$ & $7.6 \pm 0.2$ & $-(0.24 \pm 0.07)$ & $0.45 \pm 0.06$ & $39 \pm 6$ & $5.1 \pm 0.9$ \\
\hline MTA $^{(\mathrm{b})}$ & 589 & 184 & $44.2 \pm 3.6$ & $0.427 \pm 0.025$ & $1.09 \pm 0.06$ & $228 \pm 32$ & $5.2 \pm 0.07$ & $43.1 \pm 2.5$ & $0.441 \pm 0.012$ & $1.16 \pm 0.05$ & $241 \pm 18$ & $5.6 \pm 0.7$ \\
\hline Portland $^{(\mathrm{c})}$ & 120 to 420 & 20 & $16.8 \pm 0.8$ & $0.66 \pm 0.12$ & $0.7 \pm 0.1$ & $94.0 \pm 19.0$ & $5.6 \pm 0.06$ & $16.9 \pm 0.5$ & $0.64 \pm 0.02$ & $0.72 \pm 0.05$ & $94.0 \pm 7.0$ & $5.6 \pm 0.6$ \\
\hline \multicolumn{13}{|c|}{ Reference substrate-Literature } \\
\hline SS-316 & 3164 & - & 34.8 & - & 0.719 & 134 & 3.86 & & & & & \\
\hline SS-304 & 3164 & - & 40.3 & - & 0.807 & 162 & 4.02 & & & & & \\
\hline Soda-lime glass & 3000 & - & 4.6 & - & 0.147 & 10.0 & 2.15 & & & & & \\
\hline
\end{tabular}

(a) Simavi Co. Brazil, silicon grease with zinc oxide,24, 25 (b) MTA-Angelus Brazil code 820,9, 10 (c) Commercial grade Portland Cement.35

Commercial stainless steel blade.16, 26 


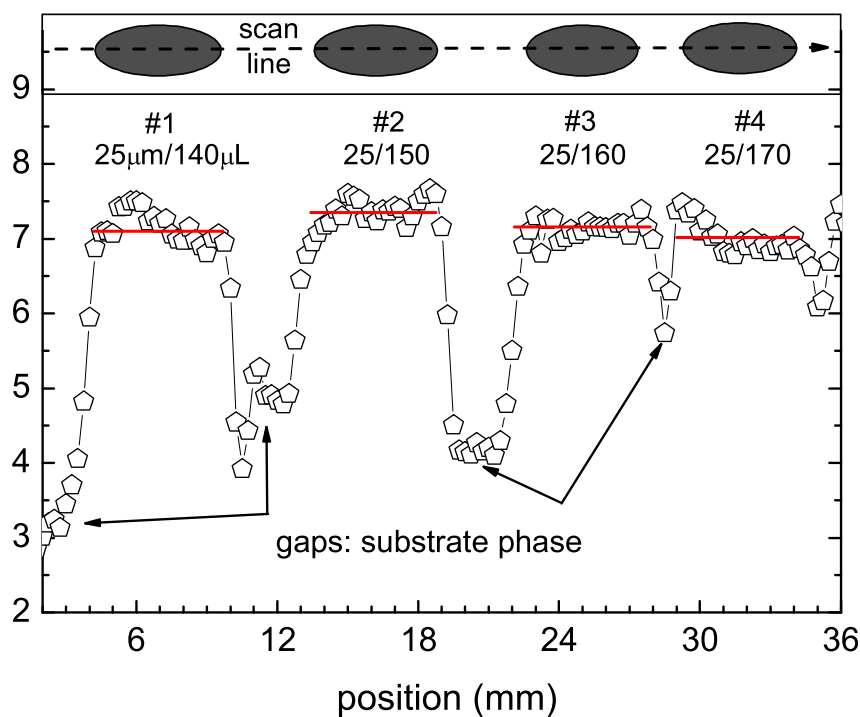

FIG. 5. PTR phases for a set of CER samples as a pictorial scanning showing phase plateaus and its small variation due porosity of CER. Lines are for averaged phase shift used in the fittings. Set prepared using the $25 \mu \mathrm{m}$ sieve and varying volumes. Scanning done at frequency of $25 \mathrm{~Hz}$.

presented in Fig. 5 and also some edge effect, when light is getting off sample surface and heating the substrate in the interval in between CER disks.

In the present study, it was considered the influence of the interface adherence layer (thermal grease) as the new layer in the model for PTR, Eq. (4). Therefore, the simulation of Eqs. (3) and (4) presented in Figs. 1 and 2 shows the existence of phase shift inversion for interfacial coefficients $\mathrm{R}$ (there $\mathrm{Rb}>0$ and converges to zero as phase goes from $-45^{\circ}$ to $0^{\circ}$ and for $\mathrm{Rb}<0$ in the other range from $0^{\circ}$ to $+45^{\circ}$ ), see Fig. 1. On the other hand, this interfacial coefficient (Rgc) with the coupling layer present goes from +1 to -1 , when phase shift goes from $-45^{\circ}$ to $+45^{\circ}$, see Fig. 2 . The phase difference was measured by subtracting the average phase of each sample to the average phase of the substrate.

\section{CER analysis}

In our knowledge, the value of thermal diffusivity of this coupling material was unknown but needed in the proposed model for the account of the adherence layer. Since the thermal property of the grease is known, CER disks were measured and data fitted using the PTR considering the conditional optical opaque with adherence model using the phase of Eq. (4). The experimental result for a $115 \mu \mathrm{m}$ thick layer of thermal coupling deposited on the stainless steel substrate was discussed earlier. Fig. 4 showed that thermal coupling fitted to Eq. (3) produced thermal diffusivity $\alpha_{\text {grease }}=(7.6 \pm 0.4) \times 10^{-3} \mathrm{~cm}^{2} / \mathrm{s}$ and thermal effusivity $\mathrm{e}_{\text {grease }}=(0.43 \pm 0.03) \mathrm{W} \mathrm{s}^{1 / 2} / \mathrm{cm}^{2} \mathrm{~s}$. These values are implemented in Eq. (4) for fitting the second layer referring to CER samples.

The fitting result for MTA commercial cement is shown in Fig. 6. Both amplitude and phase were used with normalized amplitude dropping from 1.5 to its thermally thick (the

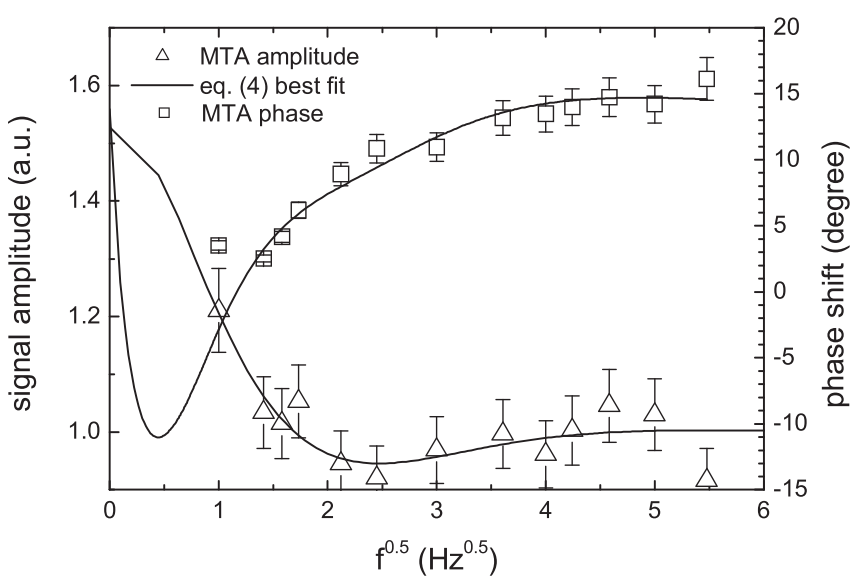

FIG. 6. PTR considering the adherence model with line being data fitting to Eq. (4) for a MTA disk $589 \mu$ m thick with layer of thermal coupling grease $184 \mu \mathrm{m}$ thick. Substrate is stainless steel and fitted parameters using amplitude (open triangles) were $\alpha_{\mathrm{MTA}} \sim(43.1 \pm 2.5) \times 10^{-3} \mathrm{~cm}^{2} / \mathrm{s}$ and $\mathrm{R}_{\mathrm{gc}}=+(0.44 \pm 0.01)$ and from phase (open squares) $\alpha_{\mathrm{MTA}} \sim(44.2 \pm 3.6)$ $\times 10^{-3} \mathrm{~cm}^{2} / \mathrm{s}$ and $R_{\mathrm{gc}}=+(0.43 \pm 0.03)$.

end point for amplitude) value 1.0 (see left side axis). On the right axis, the whole phase variation from fitting covers about $-25^{\circ}$ (from $-13^{\circ}$ for the lowest shift value to $+12^{\circ}$ for the like saturated value, or the value when the thermal wave is damped, representing its end-point value. Thermal diffusivity for MTA was $\alpha_{\mathrm{MTA}}=(44.2 \pm 3.6) \times 10^{-3} \mathrm{~cm}^{2} / \mathrm{s}$ and thermal wave interfacial coefficient $R_{\mathrm{gc}}=(0.43 \pm 0.03)$, which agrees with the model prediction from Fig. 2 that shows a typical $+0.5<\mathrm{R}_{\mathrm{gc}}<+0.0$. For the model of PTR optical opaque with adherence, the thermal wave interfacial coefficient between the stainless steel and the thermal grease is about -0.25 , an indicative that effusivity for thermal grease is lower than that for cements. Fittings are set to give $\alpha$ (thermal diffusivity) and $\mathrm{R}$ (thermal wave coefficient at interfaces) while thermal effusivity, conductivity and volume heat capacity are calculated. For MTA were obtained $\mathrm{e}_{\text {MTA }}=(1.09 \pm 0.06) \mathrm{W} \mathrm{s} \mathrm{s}^{0.5} / \mathrm{cm}^{2} \mathrm{~K}, \mathrm{~K}_{\mathrm{MTA}}=(228 \pm 32)$ $\mathrm{mW} / \mathrm{cm} \mathrm{K}$, and $\rho \mathrm{c}_{\mathrm{MTA}}=(5.2 \pm 0.07) \mathrm{J} / \mathrm{cm}^{3} \mathrm{~K}$.

By means of Eq. (3), the fitting not considering the adherence layer for CER25 $\mu \mathrm{m} / 140 \mu \mathrm{l}$ gives an $\alpha_{\mathrm{CER} 25 / 140}$ $=(40 \pm 5) \times 10^{-3} \mathrm{~cm}^{2} / \mathrm{s}$ and thermal wave interfacial coefficient $R_{b}=+(0.43 \pm 0.07)$. Errors for the fitted parameters were about $13 \%$ for thermal diffusivity and $16 \%$ for thermal wave interfacial coefficient. In order to be compared both models, a particular fitting of the CER set was picked up here as the representative one and the fitting parameter obtained from Eq. (4) was $\alpha_{\text {CER25/140 }}=(40.2 \pm 3.3) \times 10^{-3} \mathrm{~cm}^{2} / \mathrm{s}$ and interfacial coefficient $\mathrm{R}_{\mathrm{gc}}=+(0.40 \pm 0.02)$. Now the averaged errors for all CER samples (see Table I) for $\alpha$ were about $8.0 \%$ and $5.5 \%$ for the effective $\mathrm{R}_{\mathrm{gc}}$. Clearly one can see that these errors are overestimated when Eq. (3) is applied, since the true value found for $\mathrm{R}_{\mathrm{gc}}$ considering the adherence model for fitting is slightly reduced, If fittings include the influence of the coupling grease likely predicted in Eqs. (4) and (5). The difference observed figures out about $10 \%$ and considered enough to justify the inclusion of the contact effect on this interfacial coefficient, thus one must use $\Gamma$ instead $\mathrm{R}_{\mathrm{b}}$. 
Figure 7 shows the adjustment considering the optically opaque condition with influence the adhesive layer to a representative sample CER25/170 where both data amplitude and phase are plotted. The advantage of using PTR measurement of $\alpha$ and $\mathrm{R}$ is that one can use Eqs. (6) and (7) to derive other thermal parameters of the material. This thermophysics characterization is accomplished of thermal effusivity, thermal conductivity, and volume heat capacity of the cements, using the relationships $\alpha=\left(\mathrm{k} / \rho \mathrm{c}_{\mathrm{p}}\right)$ and $\mathrm{e}=(\mathrm{k} / \sqrt{ } \alpha)$, since $\mathrm{R}=(1-\mathrm{b}) /(1+\mathrm{b})$ and $\mathrm{b}=\left[\mathrm{e}_{\mathrm{s}} / \mathrm{e}_{\mathrm{c}}\right]$. Effusivity is calculated using the $\mathrm{R}$ fitted that leads to the parameter "b." For this calculation the stainless steel (SS) properties are taken into account as $\rho_{\mathrm{SS}}=8.238 \mathrm{~g} / \mathrm{cm}^{3}, \mathrm{c}_{\mathrm{p}}=0.468 \mathrm{~W} \mathrm{~s} / \mathrm{g} \mathrm{K}$, $\alpha_{\mathrm{SS}}=0.0348 \mathrm{~cm}^{2} / \mathrm{s}, \quad \mathrm{k}_{\mathrm{SS}}=0.134 \mathrm{~W} / \mathrm{cm} \mathrm{K}$, and $\mathrm{e}_{\mathrm{SS}}$ $=0.719 \mathrm{~W} \mathrm{~s}^{0.5} / \mathrm{cm}^{2} \mathrm{~K}^{16}$

Thermal conductivity is a property dependent on microstructure and measures the ability of a material to conduct heat. This dependence is best described using the expression $\mathrm{k}=\left(\alpha \rho \mathrm{c}_{\mathrm{p}}\right)$. This parameter was done for the CER and MTA samples and the values are tabulated in Table I. Thermophysical data "e, $\mathrm{K}$, and $\rho \mathrm{c}_{\mathrm{p}}$ " were calculated using the fitted values to data by means of Eq. (4) for amplitude and its phase giving $\operatorname{Rgc}$ and $\alpha$. In the calculations, the mean value of mass density was used, obtained by the buoyancy method, giving $\rho=(2.50 \pm 0.03) \mathrm{g} / \mathrm{cm}^{3}{ }^{23}$

The thermal properties derived here by means of PTR method are themselves considered new data to the best of our knowledge, since the thermal characterization of this biocompatible cement (CER) has not been reported in the previous literature. The value for thermal diffusivity CER is greater than that for a biomaterial with similar usage such as the synthetic hydroxyapatite, which comprises the major portion of minerals of teeth ${ }^{18,20}$ and present values in the literature close to $\alpha_{\mathrm{HA}} \sim 0.004 \mathrm{~cm}^{2} / \mathrm{s}$. Whereas data on thermal stability and mechanical properties can be found for CER and MTA, extensive thermophysical data for filling root materials are lacking. In addition, there is thermal data obtained by other in vitro techniques on human enamel and

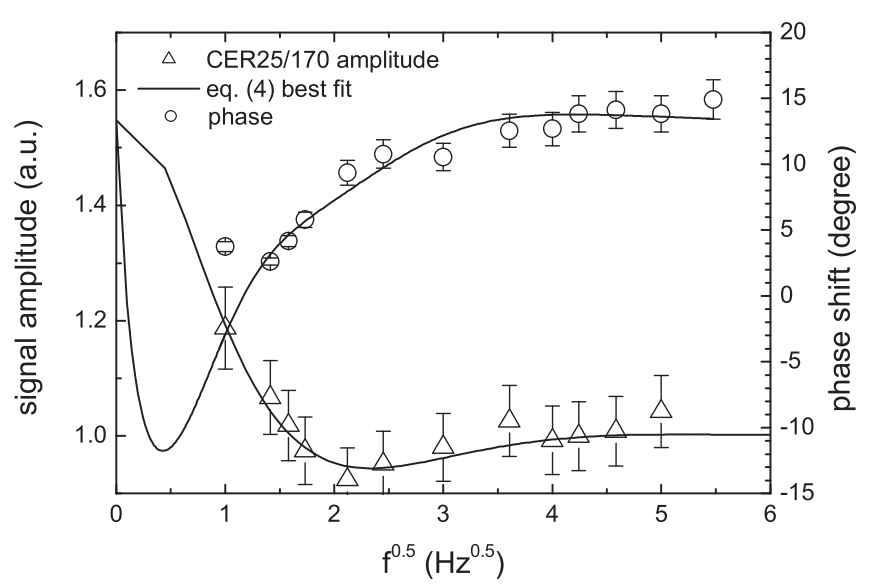

FIG. 7. PTR considering the conditional optically opaque with adherence model fitting data to Eq. (4) for CER $25 \mu \mathrm{m} / 170 \mu \mathrm{l}$ disk $565 \mu \mathrm{m}$ thick with layer of thermal coupling grease $217 \mu \mathrm{m}$ thick. Substrate is stainless steel and fitted parameters for amplitude data were $R_{\mathrm{gc}}=+(0.44 \pm 0.02)$ and $\alpha_{\mathrm{CER} 25 / 170}$ is $(36.4 \pm 2.1) \times 10^{-3} \mathrm{~cm}^{2} / \mathrm{s}$, and for phase data $R_{\mathrm{gc}}=+(0.43$ $\pm 0.03)$ and $\alpha_{\text {CER25/170 }}$ is $(37.8 \pm 3.0) \times 10^{-3} \mathrm{~cm}^{2} / \mathrm{s}$. dentin $^{28,29}$ giving values in the range of $\alpha($ enamel $)$ $\sim(0.003-0.005) \quad \mathrm{cm}^{2} / \mathrm{s}$ (for dentin $\sim 0.003 \quad \mathrm{~cm}^{2} / \mathrm{s}$ ) and $\mathrm{k}($ enamel $) \sim 9 \mathrm{~mW} / \mathrm{cm} \mathrm{K}($ for dentin $\mathrm{k} \sim 6 \mathrm{~mW} / \mathrm{cm} \mathrm{K}){ }^{30,31}$ As to compare, the typical value for natural bovine bone is $\alpha$ $\sim(0.003-0.005) \mathrm{cm}^{2} / \mathrm{s}^{32}$ and one can find typical values of $\mathrm{k}$ $\sim 5.0 \mathrm{~mW} / \mathrm{cm} \mathrm{K}$ for human rib bones and $\mathrm{k} \sim 8.0 \mathrm{~mW} / \mathrm{cm} \mathrm{K}$ for the enamel of human teeth. ${ }^{33,34}$

\section{Influence of grain size}

By means of data from Table I for CER thermal properties, some plots were done two fold, first and here discussed, the plots were against grain size but averaging all results in emulsion volume. This was necessary to try discriminating this influence on thermal properties since they presented small variation when compared sample to sample looking at them in groups, which could be better done in taking volume average for grain influence. The same was applied to the analysis of evolution of thermal properties against volume, but in taking all grain size averaged for each volume group, this case is presented further in its own section below. Following this an almost linear plot was found for each parameter and its slope was evaluated as shown in Table II. The representative picture of this analysis is shown in Fig. 8 for thermal conductivity. One can see in this figure that $\mathrm{K}$ decreases linearly with grain size and goes away from the MTA value, which is shown above by a horizontal line. This negative slope is about $(-0.26 \pm 1.43)$ but $\mathrm{K}$ values are close to that of MTA, at most between 10\% lower than MTA. For thermal diffusivity, its slope showed a small tendency to increase with grain size. The slope is close to $(0.28 \pm 0.17)$ but its averaged value is also close to that for MTA, with dispersion less than $10 \%$. Finally, for thermal effusivity the slope was $-(0.0044 \pm 0.0029)$ and for heat capacity $-(0.040$ \pm 0.035 ), the values obtained also are in agreement with MTA values with dispersion about $13 \%$ for "e" and $12 \%$ for " $\rho c_{\mathrm{p}}$," respectively. The positive slope for " $\alpha$ " maybe explained by recalling the definition of thermal diffusivity, being $\alpha=\mathrm{K} / \rho \mathrm{c}_{\mathrm{p}}$. Thus, if one expects $\rho \mathrm{c}_{\mathrm{p}}$ to be constant the slope of $\alpha$ should follows K. In fact, variables like emulsion volume and grain size can play important role in the microstructure picture and especially in the thermal properties of the CER upon its setting up. This hypothesis might be supported by porosity data and its behavior against particle size used in setting the cement formula. ${ }^{12,23,36}$ It is consensual that the increase in porosity alone can cause influence on the value of thermal diffusivity in cements, because the space, especially a small or narrow one representing voids could be filled up with gas, air for instance or any other kind produced by setting up from chemical reactions that is stored within pores. The thermal diffusivity of air and other gases are usually higher than cements, generally about 1 order of magnitude, what might elevate $\alpha$ relative to increasing grain size. Thus, for larger sizes of grains are expected larger pores in material, raising the relative volume of air in the CER matrix. In this analysis the MTA thermal properties matched those referring to particles with $38 \mu \mathrm{m}$, excepting the value for $\mathrm{K}$ that remains close to the range of $25-38 \mu \mathrm{m}$. 
TABLE II. The slopes of thermal properties for CER samples divided into two fold groups: Grain size with volume averaged and volume with grain size averaged.

\begin{tabular}{|c|c|c|c|c|}
\hline \multirow[b]{2}{*}{ Evaluation criteria } & \multicolumn{4}{|c|}{ Slopes of thermal properties measured for ${ }^{\mathrm{a}}$} \\
\hline & $\Delta \alpha$ & $\Delta \mathrm{e}$ & $\Delta \mathrm{K}$ & $\Delta \rho \mathrm{c}_{\mathrm{p}}$ \\
\hline $\begin{array}{l}\text { Increasing the grain size } \\
\text { Averaged in emulsion volume: } \\
{[\delta \mathrm{th} / \delta \mathrm{s}]_{\mathrm{v}=\text { cte }}}\end{array}$ & $0.28 \pm 0.17$ & $-(0.0044 \pm 0.0029)$ & $-(0.26 \pm 1.43)$ & $-(0.040 \pm 0.035)$ \\
\hline $\begin{array}{l}\text { Increasing the emulsion volume averaged in grain size: } \\
{[\delta \mathrm{th} / \delta \mathrm{v}]_{\mathrm{s}=\mathrm{cte}}}\end{array}$ & $-(0.08 \pm 0.16)$ & $0.0023 \pm 0.0026$ & $0.27 \pm 1.31$ & $0.016 \pm 0.031$ \\
\hline
\end{tabular}

${ }^{\mathrm{a}} \mathrm{th}=$ thermal parameters such as $\alpha, \mathrm{e}, \mathrm{K}$, and $\rho \mathrm{c}_{\mathrm{p}} ; \mathrm{s}=$ size and $\mathrm{v}=$ volume.

\section{Influence of emulsion volume}

Similar to the above discussion, here the emulsion volume is taken as the main parameter as influencing thermal properties of CER. Again due its intrinsic importance it was taken the thermal conductivity as representative properties of CER, which is plot in Fig. 9. One can see that the group at $170 \mu \mathrm{l}$ presented the closest value to the MTA, which K values increase slightly but not too far from MTA, with dispersion less than $10 \%$. This slope is now positive $(0.27 \pm 1.31)$ but $\mathrm{K}$ values are close to that of MTA and is at most between 7\% lower than MTA. The thermal diffusivity slope presented a small tendency to decrease linearly with emulsion volume with slope close to $-(0.08 \pm 0.16)$. This is in module much less than that observed by the grain size influence, but still keeping value close to that for MTA with dispersion less than 5\%. This negative slope can be explained by calling the composition of the emulsifier gel, used in preparing CER samples. Since the volume emulsion is mainly constituted by polymeric materials, which present thermal diffusivity at least 1 order of magnitude lower than cements, ${ }^{23,36-38}$ it could be expected. For thermal effusivity, the slope was $(0.0023 \pm 0.0026)$ and for heat capacity $(0.016 \pm 0.031)$, these values are in agreement with that for MTA with dispersion at most about $11 \%$ for both "e" and for " $\rho c_{\mathrm{p}}$ " Again, recalling the definition of thermal diffusivity $\alpha=\mathrm{K} / \rho \mathrm{c}_{\mathrm{p}}$ and

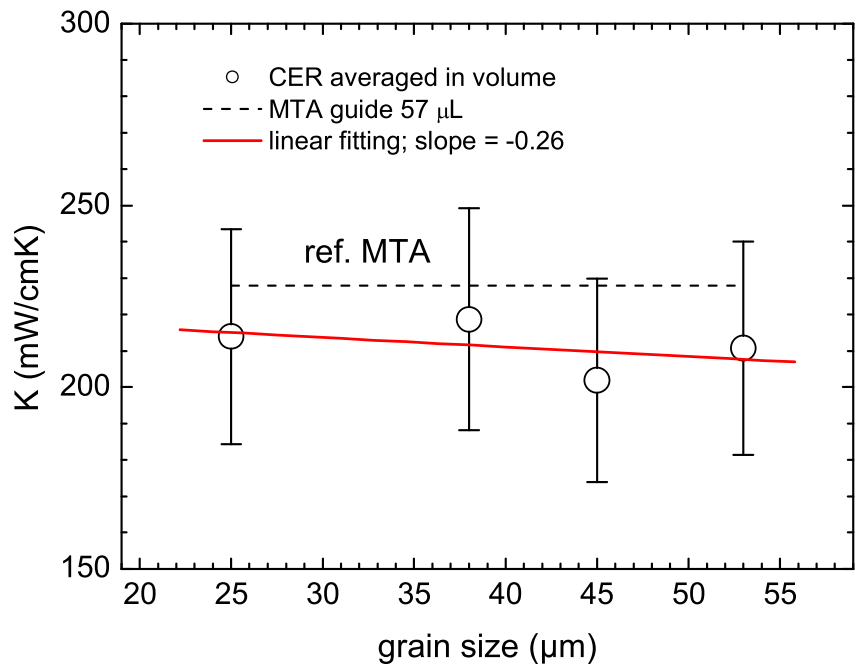

FIG. 8. Thermal conductivity behavior showing a slightly decreasing against grain size. Each data point refers to the averaged in volume for CER sample in the chosen group (here, the grain size for instance). observing that slope of " $\rho \mathrm{c}_{\mathrm{p}}$ " is positive, the immediate consequence on " $\alpha$ " is its reduction, agreeing with the reducing or negative slope of " $\alpha$."

The CER group prepared with emulsion volume at $170 \mu \mathrm{l}$ presented the closest thermal properties to MTA, excepting for thermal diffusivity that matches MTA value at $160 \mu \mathrm{l}$. Overall, results now show that behavior of the thermal properties is presenting opposite slopes compared to that discussed above for grain size effect.

If one can point out the figure of merit for this cements upon both variable, it would pointed that thermal properties similar to MTA could be matched in using particles in the range of 25 to $38 \mu \mathrm{m}$ but setting the emulsion volume close to $170 \mu \mathrm{l}$. The advantage of using this figure of merit is that the CER could be applied in root filling procedure without losing thermal matching with the buccal environment that includes tooth and its parts, enamel and dentin. As expected, thermal diffusivity is much more sensitive to the microstructure changes of CER than the parameter $\mathrm{K}$ or $\rho \mathrm{c}_{\mathrm{p}}$. Slope ratio for $(\Delta \alpha)_{\mathrm{v}} /(\Delta \alpha)_{\mathrm{s}} \cong 3.5$ and for $\left(\Delta \rho c_{\mathrm{p}}\right)_{\mathrm{v}} /\left(\Delta \rho \mathrm{c}_{\mathrm{p}}\right)_{\mathrm{s}} \cong 2.5$ while for $(\Delta \mathrm{K})_{\mathrm{v}} /(\Delta \mathrm{K})_{\mathrm{s}} \cong 0.96$ and for $(\Delta \mathrm{e})_{\mathrm{v}} /(\Delta \mathrm{e})_{\mathrm{s}} \cong 1.9$, showing the influence of microstructure related to grain size as the most influent in this parameter, what under certain reserve is reflecting the changes in heat capacity.

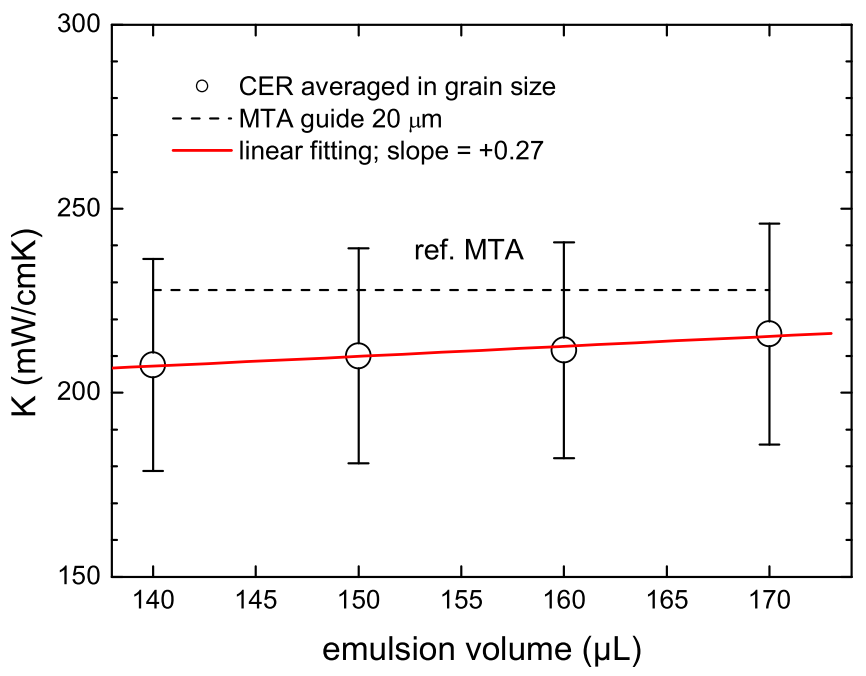

FIG. 9. Thermal conductivity of CER as a function of emulsion volume with $\mathrm{K}$ increasing smoothly with volume. Each data point refers to the averaged in grain size for CER sample in the chosen volume group. 


\section{CONCLUSION}

These results obtained for thermophysics properties of fast hardening cement CER and for the reference material MTA were presented with three main important findings. It was done by adapting PTR method for taking into account the contact influence on samples after previously deriving the thermal properties of paste itself. The first result on CER analysis leads to a correlation between thermal transport and the variations of volume of emulsion and grain size. The second one is the ability of using PTR with white light radiation instead the conventional laser heating, reducing the damages perceived as burnt spot on CER sample. The last findings could be a goal of PTR method for deriving pastry materials like the coupling fluid used as contact layer. In this fashion, PTR can be used in the analysis of conventional disk samples without building up a coating system, since thermal properties of cooling layer are previously known and method modeled properly. Finally, PTR allows a characterization of thermophysics of fast endodontic cement CER with thermal properties compatible to those of commercial MTA, highlighting the particles groups sizing between 25 and $38 \mu \mathrm{m}$ and with emulsion volume close to $170 \mu \mathrm{l}$.

\section{ACKNOWLEDGMENTS}

The authors are grateful to Brazilian agencies CAPES and $\mathrm{CNPq}$, also to the county research foundations FAPESPSão Paulo and Fundação Araucária-Paraná, for their partial financial support.

${ }^{1}$ S. J. Lee, M. Monsef, and M. Torabinejad, J. Endod. 19(11), 541-544 (1993).

${ }^{2}$ M. Torabinejad, T. F. Watson, and T. R. P. Ford, J. Endod. 19(12), 591-595 (1993).

${ }^{3}$ M. Torabinejad, C. U. Hong, F. McDonald, and T. R. P. Ford, J. Endod. 21(7), 349-353 (1995).

${ }^{4}$ R. Holland, J. A. Otoboni, V. de Souza, M. J. Nery, P. F. E. Bernabe, and E. Dezan, J. Endod. 27(4), 281-284 (2001).

${ }^{5}$ J. Camilleri, L. Formosa, and D. Damidot, Int. Endod. J. 46(9), 831-840 (2013).

${ }^{6}$ B. S. Ber, J. F. Hatton, and G. P. Stewart, J. Endod. 33(10), 1231-1234 (2007).

${ }^{7}$ H. W. Roberts, J. M. Toth, D. W. Berzins, and D. G. Charlton, Dent. Mater. 24(2), 149-164 (2008).

${ }^{8}$ G. Danesh, T. Dammaschke, H. U. V. Gerth, T. Zandbiglari, and E. Schafer, J. Endod. 39(3), 213-219 (2006).
${ }^{9}$ S. R. Sluyk, P. C. Moon, and G. R. Hartwell, J. Endod. 24(11), 768-771 (1998).

${ }^{10}$ M. A. H. Duarte, A. C. C. O. Demarchi, J. C. Yamashita, M. C. Kuga, and S. C. Fraga, Oral Surg. Oral Med. Oral Pathol. Oral Radiol. Endod. 95(3), 345-347 (2003).

${ }^{11}$ E. T. Koh, M. Torabinejad, T. R. P. Ford, K. Brady, and F. McDonald, J. Biomed. Mater. Res. 37(3), 432-439 (1997).

${ }^{12}$ A. D. Santos, J. C. S. Moraes, E. B. Araujo, K. Yukimitu, and W. V. Valerio, Int. Endod. J. 38(7), 443-447 (2005).

${ }^{13}$ A. D. Santos, E. B. Araujo, K. Yukimitu, J. C. Barbosa, and J. C. S. Moraes, Oral Surg. Oral Med. Oral Pathol. Oral Radiol. Endod. 106(3), E77-E79 (2008).

${ }^{14}$ C. A. Pela, S. Rocha, E. de Paula, and O. Baffa, Rev. Sci. Instrum. 69(9), 3392-3397 (1998).

${ }^{15}$ O. Baffa, J. Mielnik, H. Panzeri, and D. Vinha, Aust. Dent. J. 31(4), 268-272 (1986).

${ }^{16}$ D. Almond and P. Patel, Photothermal Science and Techniques (Chapman and Hall, London, U.K., 1996).

${ }^{17}$ C. A. Bennett and R. R. Patty, Appl. Opt. 21(1), 49-54 (1982).

${ }^{18}$ A. C. Bento, D. P. Almond, S. R. Brown, and I. G. Turner, J. Appl. Phys. 79(9), 6848-6852 (1996).

${ }^{19}$ E. S. Nogueira, J. R. D. Pereira, M. L. Baesso, and A. C. Bento, J. Non-Cryst. Solids 318(3), 314-321 (2003).

${ }^{20}$ T. M. Coelho, E. S. Nogueira, W. R. Weinand, W. M. Lima, A. Steimacher, A. N. Medina, M. L. Baesso, and A. C. Bento, J. Appl. Phys. 101(8), 084701 (2007).

${ }^{21}$ A. C. Bento and D. P. Almond, Meas. Sci. Technol. 6(7), 1022-1027 (1995).

${ }^{22}$ A. Mandelis, Diffusion-Wave Fields, Mathematical Methods and Green Functions (Springer-Verlag, New York, USA, 2001).

${ }^{23}$ F. B. G. Astrath, N. G. C. Astrath, M. L. Baesso, A. C. Bento, J. C. S. Moraes, and A. D. Santos, J. Appl. Phys. 111, 014701 (2012).

${ }^{24}$ C. K. Leong and D. D. L. Chung, Carbon 42, 2323-2327 (2004).

${ }^{25}$ D. A. Barker and I. Wilson, J. Am. Ceram. Soc. 88, 3116-3124 (2005).

${ }^{26}$ R. H. Bogaard, P. D. Desai, H. H. Li, and C. Y. Ho, Thermochim. Acta 218, 373-393 (1993).

${ }^{27}$ M. L. Baesso, J. Shen, and R. D. Snook, Chem. Phys. Lett. 197(3), 255-258 (1992).

${ }^{28}$ M. Lin, F. Xu, T. J. Lu, and B. F. Bai, Dent. Mater. 26, 501-513 (2010).

${ }^{29}$ D. S. Palmer, M. T. Barco, and E. J. Billy, J. Prosthet. Dent. 67(3), 325-327 (1992).

${ }^{30}$ M. Braden, Arch. Oral Biol. 9(4), 479-486 (1964).

${ }^{31}$ T. A. El-Brolossy, S. Abdalla, O. E. Hassanein, S. Negm, and H. Talaat, J. Phys. IV 125, 685-688 (2005).

${ }^{32}$ G. P. Rodríguez, A. C. Arenas, R. A. M. Hernández, S. Stolik, A. CruzOrea, and F. S. Sinencio, Anal. Sci. 17(SI), S357-S360 (2001).

${ }^{33}$ H. F. Bowman, E. G. Cravalho, and M. Woods, Annu. Rev. Biophys. Biophys. Chem. 4, 43-80 (1975).

${ }^{34}$ M. G. Sowa and H. H. Mantsch, Calcif. Tissue Int. 54(6), 481-485 (1994).

${ }^{35}$ W. M. Chirdon, W. Aquino, and K. C. Hover, Cem. Concr. Res. 37, 680-690 (2007).

${ }^{36}$ M. F. Magalhaes, R. A. Neto Ferreira, P. A. Grossi, and R. M. Andrade, J. Dent. 36(8), 588-594 (2008).

${ }^{37}$ L. Kraft, H. Enggvist, and L. Hermansson, Cem. Concr. Res. 34(3), 439-446 (2004).

${ }^{38}$ A. Elzubair, C. N. Elias, J. C. M. Suarez, H. P. Lopes, and M. V. B. Vieira, J. Dent. 34(10), 784-789 (2006). 